\title{
DEVELOPMENT OF HIGH SENSITIVE REAL-TIME PCR TO DETECT MUSTARD AND OTHER ALLERGENS OF THE FAMILY BRASSICACEAE IN FOOD SAMPLES
}

\author{
Konstantin A. Kurbakov, ${ }^{\star}$ Valentina N. Zhulinkova, Mihail Yu. Minaev \\ V. M. Gorbatov Federal Research Center for Food Systems of Russian Academy of Sciences, Moscow, Russia
}

\begin{abstract}
Keywords: real-time PCR, Brassica juncea, Brassica nigra, Sinapis alba, Brassicaceae, allergens, food products
\section{Abstract}

Mustard is a commonly used condiment including in production of other food products. As mustard is an allergen, it is necessary to control its presence. The development of PCR test-systems for its detection is complicated by the fact that this condiment can be made from seeds of various plant species (Brassica juncea, Brassica nigra, Sinapis alba) of the family Brassicaceae that are not closely related. This family includes other plant species such as white cabbage (Brassica oleracea) and rapeseed (Brassica napus), which can cause the allergic reaction, although seldom. In this connection, many authors use primers specific to many species of this family, including to allergens, to detect mustard. In this work, we used the similar strategy. To increase sensitivity, primers for the mitochondrial COX gene were selected. To increase PCR stability in analysis of deeply processed products, primers were selected for a region with a length of 61 base pair. In the work, the specificity and sensitivity of the developed PCR method was confirmed. Analyses of different products, including those that underwent deep technological processing, were carried out with these primers. Also, primers were selected to detect white mustard ( $S$. alba). When analyzing products on the presence of white mustard, characteristic regional preferences were demonstrated: this species is used in manufacturing products mainly in the UK and USA.
\end{abstract}

\section{Introduction}

Mustard is one of the most commonly used condiments. It is used in many food types, such as spice mixtures, condiments, sauces, marinades, including for meat baking, finished meat products and gastronomy products. Mustard can be prepared from plant seeds of different species: brown mustard (Brassica juncea), black mustard (Brassica nigra) and white mustard (Sinapis alba). Irrespective of a species, which seeds were used for production, mustard is an allergen. Information about its content should be indicated on a label according to TR CU022/2011 [1] and Regulation (EU) No 1169/2011 of the European Parliament and of the Council [2]. More than half of patients with an allergy to mustard also have an increased sensitivity to several other plant-derived foods and pollen [3]. It is necessary to note that the family Brassicaceae also includes such allergens as rapeseed, cabbage and broccoli.

The main mustard allergens are $2 \mathrm{~S}$ albumins of white and brown mustard seeds (Sin a 1 and Bra j 1, respectively) [4,5]. These two albumins have the similar structure and immunological properties. Therefore, when studying mustard as an allergen in a product composition, the species origin of raw materials is of no importance. For S. alba, several other allergens were revealed: $11 \mathrm{~S}$ globulin of seeds (Sin a 2) [6], non-specific lipid transfer protein (Sin a 3) and profilin (Sin a 4) [7]. It is not unlikely that new allergens will be established for B. juncea. An allergy to pollen of white cabbage (Brassica oleracea) is rare [8]. With that, about half of patients showed cross-sensitivity to mustard. In addition, the search for potential allergens of B. nigra has been performed [9].
At present, to control the mustard presence in foods, several methods based on enzyme-linked immunosorbent assay (ELISA) $[10,11]$ and polymerase chain reaction (PCR) are used. With that, ELISA methods showed false positive reactions when analyzing rapeseed [10] or egg protein and soy [11]. When developing PCR methods, the authors propose primer pairs for detection of individual species $B$. juncea and $S$. alba, as well as multiplex test-systems to detect these species together with other allergens. For example, Palle-Reisch et al. selected a primer pair for detection of $B$. juncea and B. nigra [12]. However, the reaction efficiency was different (100.6\% and $85.3 \%$, respectively) when studying DNA of each of these species. In this connection, the limit of detection for B. nigra was lower (0.005\% DNA in a sample). In another work, Palle-Reisch et al. proposed a primer-probe system for the duplex real-time PCR assay for detection of all three mustard species [13]. Sensitivity of this system was $0.0005 \%$. The use of multiplex test-systems is in highdemand for detection of allergens. For example, Köppel et al. proposed hexaplex real-time PCR to detect allergens including mustard [14]. In this work, primers proposed by Mustorp et al. were used, which were specific not only to possible mustard species, but also to rapeseed (Brassica napus), cabbage (B. oleracea), radish (Raphanus sativus). The detection limit of this reaction was $0.0032 \%$.

The models of sausage meat heated at $75-78^{\circ} \mathrm{C}$ for $15 \mathrm{~min}$. were used in $[12,13]$. Nevertheless, mustard is used in the composition of deeply processed products including canned foods and marinades. This impact leads to a significant DNA degradation. One of the approaches that increase stability 
of a PCR method in analysis of degraded DNA is reducing a length of the obtained amplicon [15].

Taking into account the presence of several allergens in the family Brassicaceae, impossibility to select a DNA region specific only to species $B$. juncea, B. nigra and S. alba, and the experience of several researchers, we proposed a primer pair specific to several species of this family. To increase PCR reliability in analysis of non-degraded DNA, primers were selected for a region with a length of 61 base pair.

It is considered that mainly species of the genus Brassica are used in Europe and Asia for mustard production, while Sinapis alba is used in the USA and Canada. In this work, we also assessed the share of mustard produced using seeds of Sinapis alba on the Russian market.

\section{Materials and methods}

Objects of investigation

Seeds of white mustard, brown mustard and white cabbage were taken as positive controls. Soy, corn and wheat were used as the negative control.

Samples of mustard available on the Russian market at retail and produced in Russia (3), the Netherlands (1), Germany (1), Poland (1), France (1), USA (3) and UK (1) were studied. The following samples of products containing mustard seeds were taken: marinated vegetables (3), sauce (3), baking chicken marinade (1) and mustard oil (1). Mustard seeds and brine were taken from samples of marinated vegetables.

\section{Sampling and DNA extraction}

Seeds were ground in a homogenizer LB20E (Waring Commercial, Torrington, Connecticut, USA). When necessary, food products were minced in a homogenizer GRINDOMIX GM 200 (Retsch, Haan, Germany). Mustard oil $(5 \mathrm{ml})$ was settled for one hour in a centrifuge SIGMA 3-18K (Sigma Zentrifugen, Osterode am Harz, Germany) with acceleration of $29700 \mathrm{~g}$ at a temperature of $10^{\circ} \mathrm{C}$. After that, the supernatant was removed and sediment was mixed in the $20 \%$ Tween 80 solution. For DNA extraction, $100 \mathrm{mg}$ of food products and control samples were taken. Liquid samples were taken with a volume of $200 \mu \mathrm{l}$. DNA extraction was carried out using Sorb-GMO-B kit (Syntol, Moscow, Russia) according to the instruction.

\section{Primer design}

The primer pairs Brass_fam and Sin_alb were complimentary to the mitochondrial COX gene and retrotrans- poson Sal-T1 (Table 1), respectively. The choice of the mitochondrial DNA region for identification of the family Brassicaceae was conditioned by its multi-copy nature, which enhanced sensitivity of the method. The DNA regions were available in the GenBank database [16]. For system design, the programs Primer-BLAST [17] and OligoAnalyzer v. 3. were used [18].

\section{Conditions for real-time PCR}

Real-time PCR was carried out using an amplifier ANK-32 (Syntol, Moscow, Russia). The reaction mixture (30 $\mu \mathrm{l})$ contained primers with a concentration of $300 \mathrm{nM}, 2.5 \mathrm{mM}$ $\mathrm{MgCl} 2$, dNTPs with a concentration of $0.25 \mathrm{mM}$ each, SynTaq polymerase with a concentration of 2.5 activity units and $5 \mu \mathrm{L}$ of extracted DNA. The components of the reaction mixture were produced by Syntol. The parameter of PCR was as follows: initial denaturation at $95^{\circ} \mathrm{C}$ for $7 \mathrm{~min}$ and 45 cycles of amplification $\left(60^{\circ} \mathrm{C}, 40 \mathrm{~s}\right.$ and $\left.95^{\circ} \mathrm{C}, 15 \mathrm{~s}\right)$. All samples were investigated in triplicate. The obtained data were analyzed using the software ANK-32 (Syntol).

Based on the results of PCR with primers Brass_fam, semi-quantitative analysis of the mustard content in the test samples was carried out by the equation:

$$
x=E^{\left(C q_{K}-C q_{T}\right)}
$$

where

$E$ is the reaction efficiency;

$C q_{K}$ is the threshold cycle of the amplification curve of the positive control;

$C q_{T}$ is the threshold cycle of the amplification curve of the sample.

Data analysis was carried out using Microsoft Excel 2016 [19].

\section{Results and discussion}

Detection of efficiency, specificity and cut-off cycles

of positive results

The short length of the PCR amplicon was used for increasing method stability when analyzing samples with degraded DNA.

To detect the reaction parameters and limit of detection, PCR with the selected primer pairs was carried out.

For analysis of primers for the Sin_alb gene, DNA of white mustard seeds and its decimal dilutions of up to $0.0001 \%$ were used. For analysis of primers Brass_fam, we used a dilution of DNA of white mustard seeds with a concentration of $100 \%$ to $0.0001 \%$. The detection limit of PCR

Table 1. Sequences and positions of the primers used in the study

\begin{tabular}{|c|c|c|c|}
\hline Primer & Primer sequence (5'-3') & Amplification region & Amplification size, bp \\
\hline Brass_fam-F & GCCGAGATCAAGGTTCAAACAAA & COX & 61 \\
\hline Brass_fam-R & CTTAAAATGTCCTTCTTCCCCGC & \\
\hline Sin_alb-F & GTACGTCTCTAATCGGCATGGAT & Retrotransposn \\
\hline Sin_alb-R & CTGCTGTTCTCTGTTTCGTGAAG & 107 \\
\hline
\end{tabular}

bp $=$ base pairs 
with primers for Brass_fam was $0.001 \%$ of the target template in a sample. This value was not lower than in similar test-systems $[12,13,14]$. The calculated coefficient of correlation of PCR was $R^{2}=0.99$; PCR efficiency was $E=2.01$. The equation of linear regression is the following:

$$
y=-3,317 x+44,97
$$

The calculated coefficient of correlation of PCR with primers Sin_alb was $R^{2}=0.99$; PCR efficiency was $E=2.03$. The equation of linear regression is the following:

$$
y=-3,2 x+51,145
$$

When using Brass_fam and Sin_alb, no non-specific annealing with samples of soy, corn, wheat was found. Nonspecific annealing was absent in the reaction between primers Sin_alb and DNA of white cabbage.

\section{Analysis of mustard condiments}

The PCR result for the sample of the US organic mustard powder was expectedly close to the Cq values of the control. Relative quantitative analysis of condiments showed that in the samples of domestic mustard, its content was in a range of 0.5 to $4.5 \%$ in reference to ground seeds. This value was $0.22 \%, 1.8 \%$ and $13.9 \%$ in mustard produced by Germany, the Netherlands and Poland, respectively. The highest content of the mustard powder was in the condiment produced by France (29.6\%) and the UK (71\%). In one US sample, a mustard proportion was $5.9 \%$, in another $0.004 \%$. Such a low value can be explained by replacement of the mustard powder with some other aromatic raw materials. It is necessary to note that product $\mathrm{pH}$ influences the ultimate value of the PCR result [20]. As vinegar is used, as a rule, in production of this condiment, the obtained values can be insignificantly lower than real.

\section{Analysis of other food products}

The authors of previous studies tested their methods on different products: cooked sausage models, sauces, spice mixes, meat spreads, fried noodles, nuggets and so on $[13,14]$. However, there were no deeply processed products among these objects. In our work, we took samples of brine from canned marinated vegetables and mustard oil besides sauces and marinades.

The PCR method allowed detecting mustard in the sauce compositions: $0.6-0.4 \%$ of the content relative to the positive control. The mustard content was $10 \%$ in the sample of marinade for baking.

The result of the quantitative analysis of the mustard oil composition was $0.005 \%$ relative to the positive control, which is explained by the technology of vegetable oil purification. This result shows that it is impossible to detect mustard oil in the composition of food products using this method. Nevertheless, this method can be used for establishing vegetable oil falsification.

Mustard DNA was revealed in the samples of marinade of canned vegetables at a level of $0.001-0.0015 \%$. With that, it is necessary to note that whole mustard seeds were added. Therefore, it was shown that sensitivity of the developed method allows identifying mustard in the composition of deeply processed products, in particular, canned foods.

Analysis of the use of S. alba seeds in production

of ready condiments and other food products

Samples with the mustard content of not lower than $0.1 \%$ were used for analysis. It was linked with lower sensitivity of PCR with primers Sin_alb. Whole mustard seeds were taken from the brine of canned products. S. alba was qualitatively detected in the products from Poland and the Netherlands as well as USA and UK. In the US and UK mustard samples, mainly white mustard was detected. With that, it should be noted that the condiment sample from the USA was denoted as Braun Mustard. In the European products $S$. alba was detected in lower quantities. It is connected with the fact that these samples belonged to the recipe of "French" mustard, which composition envisages the use of both white mustard and brown or black mustard.

\section{Conclusion}

In this work, we proposed a primer pairs to detect mustard in food samples by the PCR method. High sensitivity of the method was shown. This, in particular, allowed detecting mustard traces in deeply processed samples such as canned foods. Also, successful PCR with the sample of DNA extracted from mustard oil was carried out. Therefore, this method can be used for detection of vegetable oil falsification.

Ready condiments and products were compared regarding the use of $S$. alba seeds. Despite availability of raw materials, European manufacturers traditionally use brown and black mustard, while in the UK and USA, white mustard has been detected in condiments declared as brown mustard. Nevertheless, there are condiment types, in which seeds of the genera Brassica and Sinapis are used. In this connection, it is impossible to rely on the geographical origin of a product and use one primer pair specific only to the genus Brassica or Sinapis, when analyzing food on the mustard presence.

\section{REFERENCES}

1. Technical regulations of the Customs Union TR CU022/2011 "Food products in terms of its labeling" (approved by the decision of the customs Union Commission of December 9, 2011 № 880). Moscow, - 2011. (in Russian)

2. Regulation (EU) No 1169/2011 of 25 October 2011 on the provision of food information to consumers, amending Regulations (EC) No. 1924/2006 and (EC) No. 1925/2006 of the
European Parliament and of the Council, and repealing Commission Directive 87/250/EEC, Council Directive 90/496/EEC, Commission Directive 1999/10/EC, Directive 2000/13/EC of the European Parliament and of the Council, Commission Directives 2002/67/EC and 2008/5/EC and Commission Regulation (EC) No 608/2004. Official Journal of the European Union, L304, 18-63. 
3. Figueroa, J., Blanco, C., Dumpiérrez, A.G., Almeida, L., Ortega, N., Castillo, R., Navarro, L., Pérez, E., Gallego, M.D., Carrillo, T. (2005). Mustard allergy confirmed by double-blind placebo-controlled food challenges: clinical features and cross-reactivity with mugwort pollen and plant-derived foods. Allergy, 60(1), 48-55. https://doi.org/10.1111/j.1398-9995.2005.00644.x

4. Menéndes-Arias, L., Moneo, l., Domínguez, J., Rodrígues, R. (1988). Primary structure of the major allergen of yellow mustard (Sinapis alba L.) seed, Sin a I. European Journal of Biochemistry, 177(1), 159-166. https://doi.org/10.1111/j.1432-1033.1988. tb14357.x-i2

5. de la Peña, M. A. G., Menéndez-Arias, L., Monsalve, R. I., Rodríguez, R. (1991). Isolation and Characterization of a Major Allergen from Oriental Mustard Seeds, Bra j1. International Archives of Allergy and Immunology, 96(3), 263-270. https://doi. org/10.1159/000235505

6. Palomares, O., Cuesta-Herranz, J., Vereda, A., Sirvent, S., Villalba, M., Rodríguez, R. (2005). Isolation and identification of an 115 globulin as a new major allergen in mustard seeds. Annals of Allergy, Asthma \& Immunology, 94(5), 586-592. https://doi. org/10.1016/S1081-1206(10)61138-6

7. Angelina, A., Sirvent, S., Palladino, C., Vereda, A., CuestaHerranz, J., Eiwegger, T., Rodríguez, R., Breiteneder, H., Villalba, M., Palomares, 0. (2016). The lipid interaction capacity of Sin a 2 and Ara h 1, major mustard and peanut allergens of the cupin superfamily, endorses allergenicity. Allergy, 71(9), 1284-1294. https://doi.org/10.1111/all.12887

8. Hermanides, H. K., Laheÿ-de Boer, A. M., Zuidmeer, L., Guikers, C., Ree, R., Knulst, A. C. (2006). Brassica oleracea pollen, a new source of occupational allergens. Allergy, 61(4), 498-502. https://doi.org/10.1111/j.1398-9995.2006.01055.x

9. Khaliq, B., Falke, S., Negm, A., Buck, F., Munawar, A., Saqib, M., Mahmood, S., Ahmad, M.S., Betzel, C., Akrem, A. (2017). SAXS and other spectroscopic analysis of 125 cruciferin isolated from the seeds of Brassica nigra. Journal of Molecular Structure, 1137, 60-66. https://doi.org/10.1016/j.molstruc.2017.02.043

10. Lee, P. W., Hefle, S. L., Taylor, S. L. Lee, P.-W., Hefle, S.L., Taylor, S.L. (2008). Sandwich enzyme-linked immunosorbent assay (ELISA) for detection of mustard in foods. Journal of food science, 73(4), T62-T68. https://doi.org/10.1111/j.17503841.2008.00725.x
11. Koppelman, S. J., Vlooswijk, R., Bottger, G., Van Duijn, G., Van der Schaft, P, Dekker, J., Van Bergen, H. (2007). Development of an enzyme-linked immunosorbent assay method to detect mustard protein in mustard seed oil. Journal of food protection, 70(1), 179-183. https://doi.org/10.4315/0362-028x-70.1.179

12. Palle-Reisch, M., Wolny, M., Cichna-Markl, M., Hochegger, R. (2013). Development and validation of a real-time PCR method for the simultaneous detection of black mustard (Brassica nigra) and brown mustard (Brassica juncea) in food. Food chemistry, 138(1), 348-355. https://doi.org/10.1016/j.foodchem.2012.10.055

13. Palle-Reisch, M., Cichna-Markl, M., Hochegger, R. (2014). Development and validation of a duplex real-time PCR assay for the simultaneous detection of three mustard species (Sinapis alba, Brassica nigra and Brassica juncea) in food. Food chemistry, 153, 66-73. https://doi.org/10.1016/j.foodchem.2013.12.035

14. Köppel, R., van Velsen-Zimmerli, F., Bucher, T. (2012). Two quantitative hexaplex real-time PCR systems for the detection and quantification of DNA from twelve allergens in food. European Food Research and Technology, 235(5), 843-852. https://doi. org/10.1007/s00217-012-1806-8

15. Mano, J., Nishitsuji, Y., Kikuchi, Y., Fukudome, S., Hayashida, T., Kawakami, H., Kurimoto, Y., Noguchi, A., Kondo, K., Teshima, R., Takabatake, R., Kitta, K.(2017). Quantification of DNA fragmentation in processed foods using real-time PCR. Food chemistry, 226, 149-155. https://doi.org/10.1016/j.foodchem.2017.01.064 16. GenBank $\AA^{\circ}$. Bethesda, MD, USA: National Center for Biotechnology Information (NCBI), US National Library of Medicine; 2017. [Electronic resource: http://www.ncbi.nlm.nih.gov/ Access date 14.07.2020]

17. Primer-BLAST. Bethesda, MD, USA: National Center for Biotechnology Information, U. S. National Library of Medicine; 2017. [Electronic resource: https://www.ncbi.nlm.nih.gov/tools/primer-blast/index.cgi Access date 14.07.2020]

18. OligoAnalyzer 3.1, Integrated DNA Technologies, Inc., Coralville, IA, USA; 2017. [Electronic resource: http://eu.idtdna. com/calc/analyzer Access date 14.07.2020]

19. Microsoft Excel 2010, Microsoft, Redmond, WA, USA; 2016.

20. Bauer, T., Hammes, W. P., Haase, N. U., Hertel, C. (2004).

Effect of food components and processing parameters on DNA degradation in food. Environmental Biosafety Research, 3(4), 215-223. https://doi.org/10.1051/ebr:2005005

\section{AUTHOR INFORMATION}

Konstantin A. Kurbakov - Engineer of Laboratory of hygiene of manufacture and microbiology, V. M. Gorbatov Federal Research Center for Food Systems of Russian Academy of Sciences. 109316, Moscow, Talalikhina str., 26.

Tel: +7-495-676-63-21.E-mail: homo_ludens@vniimp.ru

https://orcid.org/0000-0003-1348-860X

* corresponding author

Valentina N. Zhulinkova - Engineer of Laboratory of hygiene of manufacture and microbiology, V. M. Gorbatov Federal Research Center for Food Systems of Russian Academy of Sciences.109316, Moscow, Talalikhina str., 26.

Tel: +7-495-676-63-21. E-mail: v.zhulinkova@fncpc.ru

https://orcid.org/0000-0001-9063-2164

Mihail Yu. Minaev - candidate of technical sciences, head of Laboratory of molecular biology and bioinformatics, V. M. Gorbatov Federal Research Center for Food Systems of Russian Academy of Sciences. 109316, Moscow, Talalikhina str., 26. Tel.: +7-495-676-79-81. E-mail: mminaev@inbox.ru

https://orcid.org/0000-0002-0038-9744

All authors bear responsibility for the work and presented data.

All authors made an equal contribution to the work.

The authors were equally involved in writing the manuscript and bear the equal responsibility for plagiarism.

The authors declare no conflict of interest.

Received 13.08.2020 Accepted in revised 01.09.2020 Accepted for publication 25.09.2020 